\title{
New bicyclic hemiacetals from the edible mushroom Ramaria madagascariensis
}

\author{
Dong-Ze Liu', Jian-Guo Li $^{2}$, Ming-Wei Zhang ${ }^{2}$ and Gang Liu ${ }^{2}$ \\ The Journal of Antibiotics (2015) 68, 137-138; doi:10.1038/ja.2014.102; published online 13 August 2014
}

Mushrooms have attracted much more attention as functional foods or physiologically beneficial medicine due to their nutritional and medicinal value and the diversity of their bioactive secondary metabolites. ${ }^{1-2}$ In recent years, these fungi have been reported to possess a variety of bioactivities, such as antitumor, antimicrobial, hypoglycemic and antioxidant. ${ }^{3-5}$ Ramaria madagascariensis, a wild edible mushroom, which belongs to the Ramariacea family, is mainly distributed in Jilin Province, Yunnan Province, and the Tibet Autonomous Region of China. This wild mushroom has traditionally been eaten by specific groups of local people and seasonally in China. However, little is known about the chemical composition and nutritional and pharmacological values of this mushroom. In our continuous screening for naturally occurring bioactive metabolites, ${ }^{6-9}$ chemical studies of the fruiting bodies of R. madagascariensis led to the isolation of two new bicyclic hemiacetals (Figure 1).

The fruiting bodies of $R$. madagascariensis (collected in Tibet, China) were supplied and identified by one of the authors (G. Liu). The voucher specimen (201004281) was deposited in the college of Agriculture and Biotechnology, Zhejiang University, China. The airdried and powdered fruit bodies of $R$. madagascariensis $(2.5 \mathrm{~kg})$ were extracted with $95 \% \mathrm{EtOH}(101 \times 3)$ at room temperature for 6 days. The EtOH extract was next partitioned between EtOAc and $\mathrm{H}_{2} \mathrm{O}$ with the organic layer evaporated in vacuo to afford the EtOAc extract (45 g). The latter was subjected to a silica gel column chromatography eluted with increasing polarities of a mixture of $\mathrm{CHCl}_{3}$ and $\mathrm{MeOH}$, and seven fractions (Fr.1-Fr.7) were obtained on the basis of TLC analysis. Fraction 3 was separated on a silica gel column eluted with petroleum ether/EtOAc $(10: 1$ to $0: 1, \mathrm{v} / \mathrm{v})$ to give five subfractions (Fr.3-1-Fr.3-5). Fr.3-3 was rechromatographed on Sephadex LH-20 $\left(\mathrm{CHCl}_{3} / \mathrm{MeOH}, 1: 1, \mathrm{v} / \mathrm{v}\right)$ followed by semipreparative reversed-phase HPLC $\left(30 \% \mathrm{CH}_{3} \mathrm{CN}\right.$ in $\mathrm{H}_{2} \mathrm{O}$ over $10 \mathrm{~min}, 30-75 \%$ over $50 \mathrm{~min}$ ) to afford compound 2 ( $5.7 \mathrm{mg}, t_{\mathrm{R}} 20.8 \mathrm{~min}$ ). Compound $\mathbf{1}$ (4.6 mg) was obtained from Fr.3-4 by Sephadex LH-20 column with $\mathrm{MeOH}$ followed by repeated column chromatography on silica gel $\left(\mathrm{CHCl}_{3} /\right.$ acetone, 10:1-2:1, v/v).

Compound 1 was obtained as a yellow amorphous powder. Its molecular formula was established as $\mathrm{C}_{18} \mathrm{H}_{27} \mathrm{NO}_{7}$ by HRESIMS data $\left(\mathrm{m} / \mathrm{z} 392.1683[\mathrm{M}+\mathrm{Na}]^{+}\right.$, calcd 392.1685$)$, which suggested six degrees of unsaturation. The IR spectrum showed absorption bands at $3380(\mathrm{OH}), 1689$ (conjugated ketone) and 1669 (amide carbonyl) $\mathrm{cm}^{-1}$. Analysis of the ${ }^{1} \mathrm{H},{ }^{13} \mathrm{C}$ and DEPT NMR spectra indicated the presence of one methyl (oxygenated), six methylenes (one oxygenated), eight methines (four olefinic, a hemiacetal and two oxygenated), and three quaternary carbons (a ketone carbonyl, an amide carbonyl and one oxygenated). Accordingly, a bicyclic structure was required for 1 to fulfill the unsaturation requirement. The ${ }^{1} \mathrm{H}-{ }^{1} \mathrm{H}$ COSY spectrum (Figure 2) revealed four ${ }^{1} \mathrm{H}-{ }^{1} \mathrm{H}$ spin systems of $\mathrm{H}-5 /$ $\mathrm{H}-6 / \mathrm{H}-7 / \mathrm{H}-8, \mathrm{H}-1 / \mathrm{H}-2 / \mathrm{H}-3, \mathrm{H}-2 / \mathrm{NH}$ and $\mathrm{H}-1 / \mathrm{OH}$. The aforementioned data, along with crucial ${ }^{3} J \mathrm{HMBC}$ correlations (Figure 2) of $\mathrm{H}-1$ to $\mathrm{C}-5, \mathrm{H}-3$ to C-9, OH-4 to C-3, C-4 and C-9, H-5 to C-3, H-7 to $\mathrm{C}-5$, and $\mathrm{H}-8$ to $\mathrm{C}-4$, led to the determination of the bicyclic core. The location of the methoxy group was indicated by the HMBC correlations from $\mathrm{OCH}_{3}$ to C-6, and $\mathrm{H}-6$ to $6-\mathrm{OCH}_{3}$. The carboxyamide side chain was inferred upon detailed ${ }^{1} \overline{\mathrm{H}}-{ }^{1} \mathrm{H}$ COSY and HMBC spectroscopic analysis. The HMBC correlation of $\mathrm{H}-2$ to $\mathrm{C}-\mathrm{1}^{\prime}$ located the carboxyamide side chain at C-2. By combining all these evidences and data, we were able to assign planar structure of compound 1. The geometries of the C-7/C-8 and C-2'/C-3' double bonds were determined to be $Z$ and $E$, respectively, on the basis of NOESY correlations of $\mathrm{H}-7$ to $\mathrm{H}-8$ and $\mathrm{H}-2^{\prime}$ to $\mathrm{H}-4^{\prime}$ together with the coupling constants of $10.5 \mathrm{~Hz}$ between $\mathrm{H}-7$ and $\mathrm{H}-8$, and $15.1 \mathrm{~Hz}$ between $\mathrm{H}-2^{\prime}$ and $\mathrm{H}-3^{\prime}$. A NOESY cross-peak observed between $\mathrm{H}-3 \beta$ and $\mathrm{H}-5$ and the large coupling constant, $J_{2,3 \beta}$, of $13.4 \mathrm{~Hz}$, indicated

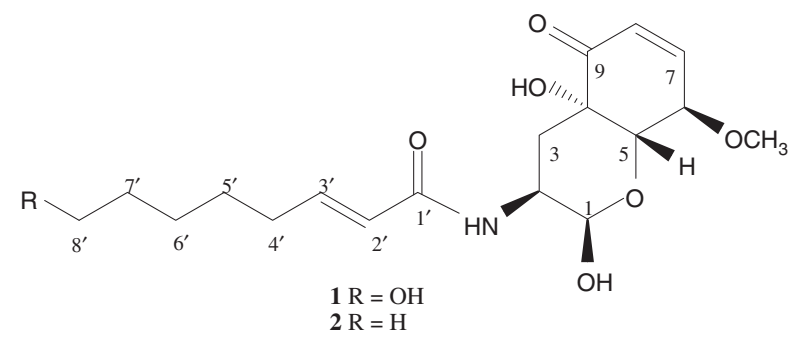

Figure 1 The structures of compounds 1 and 2 . 

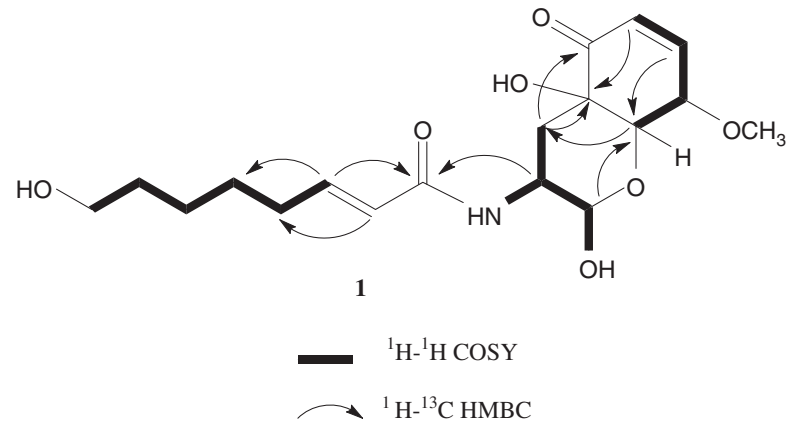

Figure 2 key COSY and HMBC correlations of 1.

Table $1{ }^{1} \mathrm{H}(500 \mathrm{MHz})$ and ${ }^{13} \mathrm{C}(125 \mathrm{MHz})$ NMR data for 1 and 2 (acetone- $d_{6}$ )

\begin{tabular}{|c|c|c|c|c|}
\hline \multirow{2}{*}{ No. } & \multicolumn{2}{|l|}{1} & \multicolumn{2}{|l|}{2} \\
\hline & $\delta_{H}$ & $\delta_{C}$ & $\delta_{H}$ & $\delta_{C}$ \\
\hline 1 & $5.19(\mathrm{dd}, 4.3,3.8)$ & 90.3 & $5.19(\mathrm{dd}, 4.3,3.8)$ & 90.3 \\
\hline 2 & $4.52(\mathrm{~m})$ & 44.8 & $4.52(m)$ & 44.8 \\
\hline 3 & $\begin{array}{c}1.98(\mathrm{dd}, 13.4,4.5) \\
1.81(\mathrm{t}, 13.4)\end{array}$ & 30.1 & $\begin{array}{c}1.98(\mathrm{dd}, 13.4,4.5) \\
1.81(\mathrm{t}, 13.4)\end{array}$ & 30.1 \\
\hline 4 & & 72.6 & & 72.6 \\
\hline 5 & $4.09(d, 8.3)$ & 73.5 & $4.09(d, 8.3)$ & 73.5 \\
\hline 6 & $4.27(\mathrm{dt}, 8.3,2.3)$ & 76.3 & $4.27(\mathrm{dt}, 8.3,2.3)$ & 76.3 \\
\hline 7 & $6.91(d d, 10.5,2.3)$ & 148.5 & $6.91(d d, 10.5,2.3)$ & 148.5 \\
\hline 8 & $5.89(d d, 10.5,2.3)$ & 126.3 & $5.89(\mathrm{dd}, 10.5,2.3)$ & 126.3 \\
\hline 9 & & 196.1 & & 196.1 \\
\hline $1^{\prime}$ & & 164.8 & & 164.8 \\
\hline $2^{\prime}$ & $6.04(\mathrm{dt}, 15.1,1.5)$ & 124.2 & $6.04(d t, 15.1,1.5)$ & 124.2 \\
\hline $3^{\prime}$ & $6.74(\mathrm{dt}, 15.1,7.0)$ & 143.8 & $6.74(\mathrm{dt}, 15.1,7.0)$ & 143.8 \\
\hline $4^{\prime}$ & $2.17(\mathrm{~m})$ & 31.5 & $2.15(\mathrm{~m})$ & 31.5 \\
\hline $5^{\prime}$ & $1.45(\mathrm{~m})$ & 28.1 & $1.44(\mathrm{~m})$ & 28.3 \\
\hline $6^{\prime}$ & $1.32(\mathrm{~m})$ & 25.7 & $1.29(\mathrm{~m})$ & 31.8 \\
\hline $7^{\prime}$ & $1.49(\mathrm{~m})$ & 32.8 & $1.28(\mathrm{~m})$ & 22.3 \\
\hline $8^{\prime}$ & $3.50(\mathrm{~m})$ & 61.7 & $0.86(t, 6.8)$ & 13.6 \\
\hline $1-\mathrm{OH}$ & $5.81(b r d, 4.3)$ & & $5.82(b r d, 4.3)$ & \\
\hline $4-\mathrm{OH}$ & 4.93(s) & & 4.93(s) & \\
\hline $9^{\prime}-\mathrm{OH}$ & $3.55(\mathrm{~m})$ & & & \\
\hline $6-\mathrm{OCH}_{3}$ & $3.47(\mathrm{~s})$ & 57.7 & $3.47(\mathrm{~s})$ & 57.7 \\
\hline $\mathrm{NH}$ & 6.88(br d, 8.9) & & 6.88(br d, 8.9) & \\
\hline
\end{tabular}

Chemical shifts $(\delta)$ are in p.p.m. and $J$ in $\mathrm{Hz}$.

the axial orientations of $\mathrm{H}-2, \mathrm{H}-3 \beta$ and $\mathrm{H}-5$, and trans ring junction, while the ${ }^{1} \mathrm{H}-{ }^{1} \mathrm{H} J$ value, $J_{1,2}$, of $3.8 \mathrm{~Hz}$, suggested an equatorial position of H-1. The large coupling constant for H-5 and H-6 $(J=8.3 \mathrm{~Hz})$ suggested $\beta$-position of $\mathrm{H}-5$ and $\alpha$-position of H- 6 . From the above analysis, the structure of 1 was established.

Compound 2 was isolated as a colorless powder. The molecular formula was determined by HRESIMS as $\mathrm{C}_{18} \mathrm{H}_{27} \mathrm{NO}_{6}$, which was one oxygen atom less than 1. The NMR, UV and IR spectroscopic data for $\mathbf{2}$ were very similar to those of $\mathbf{1}$. The significant difference was in the carboxyamide chain with the absence of a hydroxymethyl group and the presence of the methyl group $\left(\mathrm{CH}_{3}-8^{\prime}\right)$ located at $\mathrm{C}-7^{\prime}$ in 2 . The above assignment was further supported by the HMBC correlations of $\mathrm{H}_{3}-8^{\prime}$ to $\mathrm{C}-6^{\prime}$ and $\mathrm{C}-7^{\prime}$, and $\mathrm{H}_{2}-7^{\prime}$ to $\mathrm{C}-6^{\prime}$ and C- $8^{\prime}$. Detailed analysis of the 2D NMR data, in the same manner as described for $\mathbf{1}$, confirmed the identical bicyclic hemiacetal moiety. Therefore, 2 was identified as the analogue of $\mathbf{1}$, in which the terminal methyl group of the carboxyamide chain was dehydroxylated.

Structurally, compounds $\mathbf{1}$ and $\mathbf{2}$ possess chemical skeletons similar to isariotins F-J $\mathrm{J}^{10,11}$ except for the carboxyamide side chain. Accordingly, biosynthetic routes to compounds $\mathbf{1}$ and $\mathbf{2}$ may resemble those for the above compounds starting with condensation of the corresponding unsaturated carboxylic acid and L-tyrosine.

Compounds 1 and 2 were tested for their antibacterial activity against a panel of bacteria Staphylococcus aureus (ATCC6538), Bacillus thuringiensis (ATCC39765) and Bacillus subtilis (ATCC6633), using a disk diffusion method. ${ }^{12}$ However, both compounds did not show an inhibition zone at a concentration of $100 \mu \mathrm{g} /$ disk.

(1) White powder; mp $123-125^{\circ} \mathrm{C}$; $[\alpha]^{25} \mathrm{D}-81.6\left(c 0.10, \mathrm{CH}_{3} \mathrm{OH}\right)$, $\mathrm{UV}\left(\mathrm{CH}_{3} \mathrm{OH}\right) \lambda_{\max }(\log \varepsilon): 215(4.65) \mathrm{nm}$; IR (KBr) $v_{\text {max }}: 3345,3310$, 2923, 1695, 1668, 1623, 1551, $1036 \mathrm{~cm}^{-1} ;{ }^{1} \mathrm{H}$ and ${ }^{13} \mathrm{C}$ NMR spectroscopic data, see Table 1; (+)-HRESIMS $m / z 392.1683[\mathrm{M}+\mathrm{Na}]^{+}$ (calcd for $\mathrm{C}_{18} \mathrm{H}_{27} \mathrm{NO}_{7} \mathrm{Na}, 392.1685$ ).

(2) Yellow powder; mp $140-141^{\circ} \mathrm{C} ;[\alpha]^{25} \mathrm{D}-87.3$ (c 0.08 , $\left.\mathrm{CH}_{3} \mathrm{OH}\right)$, UV $\left(\mathrm{CH}_{3} \mathrm{OH}\right) \lambda_{\max }(\log \varepsilon): 216(4.33) \mathrm{nm}$; IR $(\mathrm{KBr}) v_{\max }$ : $3345,3302,2926,1686,1668,1630,1551,1033 \mathrm{~cm}^{-1} ;{ }_{1} \mathrm{H}$ and ${ }^{13} \mathrm{C}$ NMR spectroscopic data, see Table $1 ;(+)$-HRESIMS m/z 376.1734 $[\mathrm{M}+\mathrm{Na}]^{+}\left(\right.$calcd for $\left.\mathrm{C}_{18} \mathrm{H}_{27} \mathrm{NO}_{6} \mathrm{Na}, 376.1736\right)$.

1 Barros, L. et al. Antimicrobial activity and bioactive compounds of Portuguese wild edible mushrooms. Eur. Food. Res. Technol. 225, 151-156 (2007).

2 Barros, L., Baptista, P., Estevinho, L. M. \& Ferreira, I. C. F. Bioactive properties of the medicinal mushroom Leucopaxillus giganteus mycelium obtained in the presence of different nitrogen sources. Food. Chem. 105, 179-186 (2007).

3 Li, S. P., Zhang, G. H., Zeng, Q., Huang, Z. G., Wang, Y. T. \& Dong, T. T. et al. Hypoglycemic activity of polysaccharide, with antioxidation, isolated from cultured Cordyceps mycelia. Phytomedicine 13, 428-433 (2006).

4 Xiao, J. H. et al. Polysaccharides from the medicinal mushroom Cordyceps taii show antioxidant and immunoenhancing activities in a D-galactose-induced aging mouse model. Evid. Based Complement. Alternat. Med. 273-435 (2012).

$5 \mathrm{Xu}$, T., Beelman, R. B. \& Lambert, J. D. The cancer preventive effects of edible mushrooms. Anticancer. Agents. Med. Chem. 12, 1255-1263 (2012).

6 Liu, D. Z., Dong, Z. J., Wang, F. \& Liu, J. K. Two novel norsesquiterpene peroxides from basidiomycete Steccherinum ochraceum. Tetrahedron. Lett. 51, 3152-3153 (2010).

7 Liu, D. Z. et al. Vibralactone: A Lipase Inhibitor with an Unusual Fused $\beta$-Lactone Produced by Cultures of the Basidiomycete Boreostereum vibrans. Org. Lett. 25, 5749-5752 (2006).

8 Liu, D. Z., Wang, F. \& Liu, J. K. Sesquiterpenes from Cultures of the Basidiomycete Conocybe siliginea. J. Nat. Prod. 70, 1503-1506 (2007).

9 Liu, D. Z., Jia, R. R., Wang, F. \& Liu, J. K. A New Spiroaxane Sesquiterpene from Cultures of the Basidiomycete Pholiota adiposa. Z. Naturforsch. 63, 111-113 (2008)

10 Bunyapaiboonsri, T. et al. Isariotins E and F, Spirocyclic and Bicyclic Hemiacetals from the Entomopathogenic Fungus Isaria tenuipes BCC 12625. J. Nat. Prod. 72, 756-759 (2009).

11 Bunyapaiboonsri, T. et al. Isariotins G-J from cultures of the Lepidoptera pathogenic fungus Isaria tenuipes. Phytochem. Lett. 4, 283-286 (2011).

12 Wang, X. et al. Chemical Epigenetics Alters the Secondary Metabolite Composition of Guttate Excreted by an Atlantic-Forest-Soil-Derived Penicillium citreonigrum. J. Nat. Prod. 73, 942-948 (2010). 